\title{
Reconfiguração da Educação Especial: Análise da Constituição de um Centro de Atendimento Educacional Especializado ${ }^{l}$ \\ SpECIAL EDUCATION RECONFIGURATION: ANALYSis of the Constitution of A SPECIAL EDUCATION SERVICE CENTER
}

\author{
Claudio Roberto BAPTISTA2 \\ Luciane Torezan VIEGAS ${ }^{3}$
}

\begin{abstract}
RESUMO: o presente estudo teve como objetivo compreender o processo de reconfiguração das proposiçóes que vinculam a educação especial e a educação regular dos alunos com deficiência, considerando o investimento em espaços alternativos - centros de atendimento - como possibilidade de apoio complementar à escolarização. A pesquisa, de caráter qualitativo, no plano da ação metodológica, investiu prioritariamente na análise documental, no contexto de uma rede pública municipal na região metropolitana de Porto Alegre/RS. O estudo investiu na reflexão baseada em pesquisas que abordam a temática das políticas públicas educacionais, tendo como referencial prioritário a abordagem do ciclo de políticas segundo as proposiçóes de Stephen Ball. Conclui-se que a reconfiguraçáo da educaçấo especial nessa rede municipal de ensino tenha se reestruturado com base na obrigatoriedade da dupla matrícula como argumento legal que impulsionou as práticas no sentido de tornar a escolarização dos alunos com deficiência obrigatória nas escolas regulares, nas classes comuns. Essa reconfiguração teve como eixo a transformação da escola especial pública municipal, que atendia alunos com deficiência, em centro de atendimento educacional especializado.
\end{abstract}

PALAVRAS-CHAVE: Educação Especial. Atendimento Educacional Especializado. Inclusão Escolar.

\begin{abstract}
This study aimed to understand the reconfiguration process of the propositions that bind special education and the regular education of students with disabilities, considering the investment on alternative spaces - such as specialized service centers - as a possibility to complement support to schooling. As a qualitative research study in the methodological action plan, the study based on the analysis of documents in the context of a municipal public education system in Porto Alegre/RS metropolitan area. The study was based on research that approach public policies of education topics, having as main reference the works of Stephen Ball on policy cycle. It is concluded that the special education reconfiguration in this municipal system has been restructured based on the double mandatory enrollment as a legal argument that boosted the practices to make the schooling of students with disabilities mandatory in regular schools, in regular classes. This reconfiguration had as its axis the transformation of the municipal public special schools that served students with disabilities in special education service centers.
\end{abstract}

KEYWORDS: Special Education. Special Education Services. School Inclusion.

\section{INTRODUÇÃo}

O presente estudo traz à discussão temas contemporâneos, quando se consideram as pesquisas na área da Educação Especial. No contexto atual, em que se proliferam propostas e discussões que envolvem a escolarização dos alunos com deficiência ${ }^{4}$, há necessidade de se

\footnotetext{
${ }^{1}$ http://dx.doi.org/10.1590/S1413-65382216000300009

${ }^{2}$ Docente da Universidade Federal do Rio Grande do Sul, Programa de Pós-Graduação em Educação (PPGEDU/UFRGS). Porto Alegre, RS, Brasil. baptistacaronti@yahoo.com.br

${ }^{3}$ Doutora em Educação pela Universidade Federal do Rio Grande do Sul (UFRGS) e Coordenadora de Graduaçấo do Centro Universitário Metodista IPA. Porto Alegre, RS, Brasil. lucianeviegas202@gmail.com

${ }^{4}$ A fim de esclarecer a opção teórica e a utilização dos conceitos relativos à população historicamente atendida pela educação especial, no âmbito deste texto, será adotada a nomenclatura "pessoas com deficiência" para fazer referência a "pessoas com deficiência, transtornos globais do desenvolvimento e altas habilidades-superdotação" e também para apontar o "alunado" desta modalidade de educação. Durante muito tempo, a designação "pessoas com necessidades educacionais especiais" foi utilizada nos textos legais e em orientaçóes do MEC referentes às pessoas com deficiência. No entanto, entende-se que a designação "necessidades educacionais
} 
refletir, discutir, investigar e propor alternativas que possibilitem e garantam, no âmbito legal e escolar, a educação com qualidade de alunos com deficiência, transtornos globais do desenvolvimento ou altas habilidades - superdotação.

A Constituição Federal de 1988 (BRASIL, 1988), em seu artigo 206, define que "o ensino será ministrado com base no seguinte princípio: I - igualdade de condiçóes para o acesso e a permanência na escola [...]". Nessa perspectiva, considerando a realidade de oferta e de atendimento aos alunos com deficiência no país, julga-se de fundamental importância a realização de estudos que tratem das estratégias utilizadas pelos diferentes entes envolvidos com a educação pública (agentes do Ministério da Educação, gestores públicos municipais e estaduais, professores de instituiçóes públicas e privadas, entre outros) na configuração de possibilidades de garantia do direito de acesso e de permanência assinalado na Constituição Federal (BRASIL, 1988).

Historicamente, esta parcela da população é atendida tardiamente na educação formal e de maneira distante da real necessidade, isto é, muitas crianças e jovens com deficiência não chegam a se escolarizar. As novas configurações de atendimento às pessoas com deficiência nas diferentes áreas como educação, saúde, transporte, cultura, lazer, assistência e previdência social acontece de modo lento, acompanhando o longo caminho da definição de direitos ${ }^{5} \mathrm{e}$ de construção da cidadania no Brasil e no mundo. Chegou-se ao fim do período colonial no Brasil, com a "maioria da população excluída dos direitos civis e políticos e sem a existência de um sentido de nacionalidade" (CARVALHO, 2003, p.25).

Os recentes estudos, na área da educação e da educação especial, têm apontado a necessidade de se compreender como as políticas públicas educacionais são definidas, propostas e elaboradas e, mais particularmente, implementadas nos âmbitos das redes públicas e privadas nos municípios, estados e no Distrito Federal (BAPTISTA, 2011).

A nova perspectiva proposta pela Política Nacional de Educação Especial na Perspectiva da Educação Inclusiva (BRASIL, 2008a) traz discussóes que se constituíram como basilares da área da educação especial, uma vez que os espaços destinados ao atendimento de alunos com deficiência no país foram definidos ao longo do tempo, demarcados e referendados por diferentes grupos e, por vezes, pouco questionados no que se refere à modalidade de educação especial. Escolas e classes especiais constituíram-se como locais considerados mais adequados e especializados para atendimento de pessoas com deficiência, marcadamente singulares em função dos conhecimentos específicos dos profissionais que atuavam nesses locais; em geral com formação peculiar e considerados experts nas deficiências. Nesse contexto, surgem alguns questionamentos: como romper com esta perspectiva e avançar para o que se estabeleceu a partir da Política Nacional de Educação Especial (BRASIL, 2008a), que define que os alunos com deficiência devem ser incluídos na rede regular de ensino? Como tornar a educação espe-

especiais" abranja as pessoas com deficiência, transtornos globais do desenvolvimento e altas habilidades-superdotação, mas não se restrinja a esse grupo, uma vez que qualquer criança poderá apresentar, em algum momento de sua escolarização, dificuldades de aprendizagem, o que caracteriza a utilização do termo "necessidades educacionais especiais".

${ }^{5}$ Encontramos em Carvalho (2003) as seguintes definiçôes referentes aos direitos: Direitos Civis são direitos fundamentais à vida, à liberdade, à propriedade, à igualdade perante a lei, à garantia de ir e vir de escolher o trabalho, de manifestar o pensamento, de organizar-se, de ter respeitada a inviolabilidade do lar e da correspondência, de não ser preso a nấo ser pela autoridade competente e de acordo com as leis, de não ser condenado sem processo regular legal. Direitos Políticos dizem respeito à participação do cidadão no governo da sociedade. Direitos Sociais garantem a participação na riqueza coletiva, incluem o direito à educaçáo, ao trabalho, ao salário justo, à saúde, à aposentadoria. 
cial complementar ou suplementar e não mais substitutiva? Que caminhos, que transição seria possível com base nessas premissas?

Especificamente no caso da educação especial, para se compreender as propostas de escolarização e a destinação de recursos, destaca-se o Decreto no 6.571 (BRASIL, 2008b) e, posteriormente, o Decreto no 7.611 (BRASIL, 2011), que apontam para a perspectiva da dupla matrícula como um caminho para garantir o financiamento da educação de alunos com deficiência na escola regular, nas classes comuns e, concomitantemente, no Atendimento Educacional Especializado (AEE). O Decreto no 7.611 de 2011 (BRASIL, 2011) rompe com uma prática que tem sido, ao mesmo tempo, referendada historicamente e questionada na área da educação especial, caracterizada pela escolarização em espaço especializado, nas escolas ou em classes especiais, mas distante das classes comuns e das escolas regulares. A partir desses Decretos, essa prática tende a se alterar significativamente e a escolarizaçáo dos alunos com deficiência passa a compor os discursos, considerando a perspectiva legal.

Cabe aqui um esclarecimento no que se refere às metas anunciadas na proposta de título desse artigo. A palavra configuração $0^{6}$ remete à forma aparente como algo se apresenta, conjunto de parâmetros, forma de funcionamento. Levando em consideração, portanto, as mudanças advindas da legislação, que impulsionaram transformaçôes no modo como histórica e culturalmente se via a educação especial na rede estudada, analisando as peculiaridades e nuances de cada local. Essa investigação propôs a busca da compreensão de um momento em que se reconfiguram ou se configuram novamente os inúmeros elementos que compóem a forma como os alunos com deficiência são escolarizados em uma rede municipal.

Nesse contexto, o estudo ora apresentado, realizado na rede pública municipal do município de Cachoeirinha, localizado na regiāo metropolitana de Porto Alegre/RS, teve como objetivo compreender o processo de reconfiguração das proposiçóes que vinculam a educação especial e a educaçáo regular dos alunos com deficiência, considerando o investimento em espaços alternativos - centros de atendimento - como possibilidade de apoio complementar à escolarização. Investigou-se, portanto, o processo de transformação de uma escola especial municipal em centro de atendimento educacional especializado.

\section{Metodologia da PESQUiSA: CAMINHOS TRILHADOS}

No presente estudo a proposta foi realizar uma análise contextual de uma política que foi se constituindo em âmbito nacional e se materializou, na falta de melhor termo, na reestruturação da perspectiva de atendimento local aos alunos com deficiência. Os estudos de políticas educacionais vêm se configurando no Brasil como um campo distinto e em busca de consolidação. Não se sustenta, neste texto, numa visão linear e racional do processo de elaboração e de implementação de políticas, já superado por visóes menos fragmentadas e mais dinâmicas de como se constituem as políticas no âmbito local municipal (MAINARDES; FERREIRA; TELLO, 2011).

${ }^{6}$ Configuração: [1] a forma exterior de um corpo; conformação, aspecto, figura, feitio. [2] Posição aparente de dois ou mais astros na esfera celeste. [...] [4] Conjunto de parâmetros, componentes, periféricos e programas que determinam as possibilidades e a forma de funcionamento de um computador, de seu sistema operacional e de seus aplicativos. [5] Modo como estão ligados, uns aos outros, os átomos de uma molécula. (FERREIRA, 2004, p.521). 
Assim, pretende-se trazer elementos da abordagem do ciclo de políticas para este estudo, no intuito de utilizar a mesma como perspectiva metodológica. Segundo Ball (2009)7, o ciclo de políticas ${ }^{8}$ é uma maneira de pesquisar e teorizar as políticas e não diz respeito à explicação das mesmas. Desta forma, no decorrer do texto, pretende-se favorecer a compreensão acerca de como as políticas locais são produzidas, o que elas pretendem e quais são seus efeitos no âmbito da organização local.

Nesse contexto, destaca-se que o estudo teve como foco a reestruturação da educação especial para o sistema municipal de ensino, no período de 2008 a 2013, sendo trazidos neste artigo elementos coletados pela análise documental. Essa estratégia auxiliou a pensar as políticas públicas voltadas para a educação especial, tanto no âmbito nacional quanto local, possibilitando perceber as nuances e tramas que se estabeleceram na ressignificação interpretativa dos textos nacionais e na produção das políticas locais.

As produçóes e registros existentes na rede se constituíram como fonte de informaçóes, possibilitando a análise de documentos. Além disso, houve a análise de revistas publicadas pela Secretaria Municipal de Educação (CACHOEIRINHA, 2011b), bem como do documento da II Constituinte Escolar (CACHOEIRINHA, 2010) da rede municipal. Ainda no que se refere aos documentos consultados, informativos do Conselho Municipal de Educação (CACHOEIRINHA, 2011a) e publicaçóes legais exaradas pelo mesmo, relacionadas com a temática da pesquisa, como pareceres e resoluçóes foram consultados.

A análise dos documentos permitiu compreender diferentes aspectos da constituição da reestruturação da rede municipal para atender aos princípios da Política Nacional de Educação Especial (BRASIL 2008a), dentre outros aspectos. No intuito de indicar algumas possibilidades de análise dos dados coletados, conforme anteriormente apontado, a abordagem do ciclo de políticas constitui-se como um referencial útil para a avaliação de programas e políticas educacionais, “[...] uma vez que permite uma análise crítica da trajetória de políticas educacionais desde sua formulação inicial até a implementação no contexto da prática e seus efeitos" (MAINARDES, 2006, p.48).

Considerando essa perspectiva teórica, o autor referido acima critica a visão prevalente de que a política é algo que é "feito" para as pessoas. Como primeiros beneficiários, as pessoas praticam as políticas e são afetadas pelas mesmas. A abordagem de Ball (1994; 2006) defende que as políticas colocam problemas para seus sujeitos, problemas que precisam ser resolvidos no contexto.

Entende-se que na abordagem de Mainardes (2006) o ciclo de políticas admite que os professores, gestores e demais envolvidos exerçam um papel ativo no processo de interpretação e reinterpretação das políticas educacionais e, nesse sentido, seria uma das possibilidades para avaliar a implantação das políticas nacionais para a educação especial nas redes municipais. Ressalta-se que o que os professores e gestores pensam e acreditam têm implicaçóes determinantes quanto ao processo de implementação das políticas educacionais. Assim, conforme esse

\footnotetext{
${ }^{7}$ Stephen J. Ball, professor do Instituto de Educação da Universidade de Londres, diretor associado do Centro de Estudos Críticos de Políticas Educacionais deste mesmo Instituto. Dentre inúmeros temas, como teoria da organizaçấo escolar, etnografia, micropolítica, reformas educacionais, escolha das escolas pelos pais, impacto das reformas sobre o trabalho, identidade dos professores, também aborda o ciclo de políticas (BALL, 2009).

${ }^{8}$ Neste estudo, o ciclo de políticas refere-se unicamente à abordagem de Ball e Bowe (1992).
} 
autor, o texto das políticas terá uma pluralidade de leituras, em razão da pluralidade de leitores, o que abre espaço para o entendimento da complexidade e abrangência de uma proposição política, bem como da arena em que conflituam diferentes perspectivas.

\section{CONTEXTUALIZAÇÃO DA REDE MUNICIPAL DE ENSINO: DA ESCOLA ESPECIAL AO ATENDIMENTO EDUCACIONAL ESPECIALIZADO}

O município de Cachoeirinha, localizado no Rio Grande do Sul, limítrofe com Porto Alegre, conta com 118.278 habitantes que se dividem em $44 \mathrm{~km}^{2}$ de área territorial, e a taxa de urbanização atinge 100\% (BRASIL, 2010).

O município de Cachoeirinha conta com 102 escolas, sendo 14 estaduais, 33 municipais e 55 particulares, cadastradas no Educacenso. Dezessete dessas escolas possuem Salas de Recursos, sendo 16 municipais e uma estadual (BRASIL, 2013). Sabe-se que na rede pública municipal há 14 Salas de Recursos Multifuncionais (SRM) em escolas de ensino fundamental e duas SRM em escolas de educação infantil.

Observa-se que, em relação à educação especial, a rede municipal é a que mais atende os alunos nos diferentes níveis de ensino, visto que são 213 alunos com deficiência nos anos iniciais e 71 matrículas nos anos finais do ensino fundamental. A rede estadual totaliza 71 no ensino fundamental e a rede privada apenas 22 alunos com deficiência matriculados (BRASIL, 2013). No entanto, como a rede municipal não oferta ensino médio, os 25 alunos com deficiência matriculados nesta etapa de ensino encontram-se na rede estadual e três alunos na rede privada.

Em princípio, não há registros precisos no município de quando se iniciou o atendimento a alunos da educação especial na rede. Sabe-se que em 1975 já havia no município de Cachoeirinha atendimento aos chamados excepcionais ${ }^{9}$ em uma escola regular da rede, que contava com classes especiais. Direção, professores e pais de alunos com deficiência solicitaram o desmembramento do serviço de educação especial em uma escola especial (VASQUES; MARQUES, 2012). Assim, a única escola especial do município foi criada e denominada pelo Decreto Municipal no 382, de 15 de abril de 1977, que desmembra a classe especial de uma escola regular da rede municipal.

Nesse contexto, infere-se que a rede municipal inicia seu trabalho de atendimento às pessoas com deficiência pela criação de classes especiais dentro das escolas regulares, seguindo uma tendência nacional. Portanto, na década de 1970, com a criação da escola especial, há uma separação de público-alvo e os alunos são classificados para ingressarem na escola ou na classe especial, conforme condiçóes individuais.

$\mathrm{Na}$ rede estudada, nas décadas de 1980 e 1990, a escola especial se organiza, então, na tentativa de enturmar os alunos por idade, e os professores passam a investir na alfabetização como uma possibilidade, utilizando teorias e práticas que nos anos 1990 estavam em discussão na rede municipal de ensino. No decorrer dos 34 anos de existência da escola especial na rede municipal, oscilam os investimentos em termos de atendimento educacional e atendimento clínico-médico, dependendo do período histórico e da perspectiva teórica dos profissionais e gestores responsáveis em cada período.

${ }^{9}$ Excepcional, termo usado à época para se referir às pessoas com deficiência intelectual. 
Interessante perceber que a forma como vai se constituindo o serviço de atendimento nesta rede municipal perpassa diferentes instâncias locais, diferentes secretarias e há investimento do Poder Público no atendimento às necessidades dos alunos com deficiência.

Em 2005, a escola especial adotou a organização curricular por Ciclos de Formação, possibilitando aos alunos com deficiência ingressarem aos quatro anos e permanecerem até os vinte e um anos de idade. Nesse mesmo ano, a escola especial que atendia quase que exclusivamente alunos com deficiência mental passou a atender alunos com transtornos, autismo e diferentes síndromes (MARQUES, 2012).

Desta forma, de 2005 em diante, a escola especial caracterizou-se por intensas movimentações com efetivação de uma proposta pedagógica e dos planos de estudo, com a mudança no perfil do alunado da escola especial, formaçóes continuadas constantes para atender às demandas de aprendizagem dos alunos da escola especial e encaminhamentos dos alunos com deficiência para as escolas regulares. Também a Política Nacional de Educação Especial na perspectiva da Educação Inclusiva (BRASIL, 2008a) representou importante marco para que a mantenedora se mobilizasse, constituindo um Fórum de Discussão, o que desencadeou o encerramento das atividades da escola especial e a criação do Centro de atendimento educacional especializado.

Convém referir que Cachoerinha manteve a escola especial e as classes especiais em escolas regulares, conforme as políticas foram sendo publicadas (BRASIL, 2001a, 2001b). Durante a década de 2000, a fim de dar conta da oferta de espaços específicos para atendimento dos alunos com deficiência na escola regular, a rede municipal foi se organizando para receber os subsídios do Governo Federal. Intensifica-se, então, a criação, nas escolas regulares, das salas de recursos multifuncionais, como forma de atendimento às necessidades dos alunos da educação especial.

No ano de 2008, a rede municipal de ensino contava com quatro salas de recursos e, em 2013, esse número foi ampliado para 14 salas de recursos multifuncionais, atendendo aos alunos por região. A rede estudada constituiu o AEE e investiu largamente na formação continuada de professores. Nesse período, amplia-se a formação, que deixa de ser dirigida exclusivamente ao docente que trabalhava diretamente com o aluno com deficiência, e passa a abranger todos os professores, equipes pedagógicas e funcionários atuantes em cada uma das escolas regulares (CACHOEIRINHA, 2011c).

Percebe-se o quanto as mudanças referentes ao tipo de atendimento ofertado aos alunos com deficiência vão se configurando a partir de 2007. Inicialmente, a escolarização dos alunos com deficiência se centra, na maior parte dos casos, na escola especial, mas gradativamente as SRM vão se constituindo na rede municipal de Cachoeirinha, substituindo as classes especiais ainda existentes nas escolas regulares. Ampliam-se as salas advindas do Programa de Implantação das Salas de Recursos Multifuncionais (BRASIL, 2007) e os alunos com deficiência, em sua maioria, passam a se matricular nas escolas regulares, compondo as classes comuns e recebendo AEE no contraturno.

Assim, no final do ano de 2010, constituiu-se um grupo, por solicitação da mantenedora $^{10}$, liderado por profissionais da escola especial, com o intuito de dedicar horas de

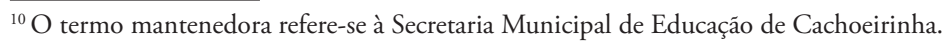


estudo e debate sobre o atendimento educacional especializado no município. Pais, professores, funcionários, gestores, diretores da escola especial, de escolas regulares e de educação infantil debateram o tema, em espaço institucional que se constituiu como um Fórum de Discussão sobre o futuro da escola especial. Logo, o debate centrou-se nas reflexóes e propostas de alternativas para transformar a escola especial em centro de atendimento educacional especializado (VASQUES; MARQUES, 2012).

O Fórum de Discussão manteve uma sistemática de encontros entre os anos de 2010 e 2011 com uma participação variada, segundo as atas dos encontros (CACHOEIRINHA, 2011d). Várias questóes foram tratadas nesses momentos, que também foram espaços para que os integrantes pudessem expressar suas dúvidas, medos, críticas e dialogar sobre o significado de tal mudança.

No que se refere aos motivos alegados para cessar as atividades da escola especial e criar um centro de atendimento educacional especializado, a dimensão legal parece ter sido parte da estratégia de convencimento, por meio do diálogo, utilizada pelos gestores da rede municipal a fim de buscarem apoio das famílias neste processo (CACHOEIRINHA, 2011e).

A Resolução CNE/CEB no 4 de 2009 reporta-se ao Decreto no 6.571 (BRASIL, 2008b) e aponta que, na implementação, os sistemas de ensino devem matricular os alunos com deficiência, transtornos globais do desenvolvimento e altas habilidades/superdotação nas classes comuns do ensino regular e no AEE, sendo este ofertado em SRM ou em Centros de AEE da rede pública ou de instituiçóes comunitárias, confessionais ou filantrópicas sem fins lucrativos.

Destaca-se que, além de indicar a dupla matrícula nas escolas regulares da rede pública, o Decreto também indica, primeiramente, o AEE oferecido na própria escola ou em outra da rede pública, tanto em SRM quanto nos Centros. No entanto, há espaço ainda para que instituições de educação especial comunitárias, confessionais ou filantrópicas sem fins lucrativos continuem oferecendo o AEE através de Centros.

No governo atual ${ }^{11}$ foi publicado o Decreto no 7.611 (BRASIL, 2011a), que "dispóe sobre a educação especial, o atendimento educacional especializado e dá outras providências", revogando o Decreto no 6.571 (BRASIL, 2008b). A principal alteração diz respeito aos serviços de apoio especializado, denominados AEE e "compreendidos como o conjunto de atividades, recursos de acessibilidade e pedagógicos organizados institucionalmente e continuamente" $\left(\operatorname{art} .2^{\circ}\right.$, par. $\left.1^{\circ}\right)$. Neste mesmo artigo, o AEE é referendado como complementar à formação dos estudantes com deficiência, transtornos globais do desenvolvimento, como apoio permanente e limitado no tempo e na frequência dos estudantes às salas de recursos multifuncionais e suplementar à formação de estudantes com altas habilidades ou superdotação.

Chama a atenção, em modo especial no Decreto no 7.611 (BRASIL, 2011a), a ênfase ao financiamento do AEE para instituições comunitárias, confessionais ou filantrópicas sem fins lucrativos, conveniadas com o Poder Público. Esse Decreto parece responder às manifestaçóes de diferentes instituiçóes nessa categoria, as quais se posicionaram publicamente quando da aprovação do Decreto no 6.571 (BRASIL, 2008b). Tal fato reforça a concepção de autores como Mainardes $(2006 ; 2009)$ que entendem as políticas como resultado de um jogo de forças

${ }^{11}$ Governo Dilma Russef, de 2011 a 2014. 
que se estabelece entre os diferentes atores na disputa por espaço e por garantia de formas de viabilização de práticas por vezes históricas. No caso da educação especial, historicamente, os governantes dividiram com a sociedade civil e instituiçóes voltadas para a educação especial a responsabilidade pela oferta do atendimento às pessoas com deficiência.

Nesse sentido, a rede pública municipal de Cachoeirinha é exemplo de um contexto em que o poder público local assume, mesmo que parcialmente, a responsabilidade pela educação especial, uma vez que não há convênios com a rede privada para atendimento a essa clientela. Dessa forma, ao final de 2010, após inúmeros encontros do Fórum de Discussão, foi tomada a decisão de preparar no ano seguinte a rede para a cessação das atividades da escola especial e para a criação do centro municipal de atendimento educacional especializado.

\section{A RECONFIGURAÇÃo da EDUCAÇÃo ESPECIAL: A CONSTITUIÇÃo DE UM CENTRO DE ATENDIMENTO EDUCACIONAL ESPECIALIZADO}

Considera-se importante destacar que qualquer decisão que envolva a forma de atendimento aos alunos com deficiência na rede pública municipal, como a observada em Cachoeirinha, vem acompanhada de inúmeras disputas, entraves, reflexóes, dúvidas e resistências dos atores envolvidos, sejam professores, gestores, pais ou alunos. Na referida rede, o contexto mostrou o quanto os encontros de formação, as práticas alternativas e a convivência com diferentes concepçóes fizeram parte da construção de um novo momento em que se reconfiguram as formas de atendimento do alunado da educação especial (CACHOEIRINHA, 2011a).

Em 26 de novembro de 2012, o Conselho Municipal de Educação de Cachoeirinha (CME) aprovou, por unanimidade, a Resolução no 18 de 2012, que estabelece normas para o credenciamento e a autorização para funcionamento dos Centros de Atendimento Educacional Especializado e dá outras providências (CACHOEIRINHA, 2012). Há, nesse caso, destaque, no art. $1^{\circ}$, para a integração dos Centros que forem criados no Sistema Municipal de Educação de Cachoeirinha. Além disso, conforme o parágrafo $1^{\circ}$ deste mesmo artigo:

Considera-se Centro de Atendimento Educacional Especializado (CAEE) a instituição organizada para desenvolver plano de atendimento educacional especializado a alunos com deficiência, transtornos globais do desenvolvimento e altas habilidades/superdotação, matriculados na rede regular de ensino (CACHOEIRINHA, 2012).

A Resolução CME no 18 de 2012, portanto, reforça que os alunos matriculados no Centro precisam, necessariamente, estar matriculados nas escolas da rede regular de ensino, nesse sentido, configurando-se como um espaço de atendimento complementar ou suplemen$\operatorname{tar}$ (CACHOEIRINHA, 2012). O documento conceitua o AEE como "o conjunto de atividades e recursos pedagógicos e de acessibilidade, organizados institucionalmente, prestado de forma complementar ou suplementar à formação dos alunos público-alvo da educação especial, matriculados no ensino regular" (Art. $1^{\circ}$, par.1).

Na prática, segue-se o que vem acontecendo em termos de constituição do serviço, pois há as SRM e os Centros. A diferenciação viria com o atendimento do aluno com deficiência nas classes comuns das escolas regulares, rompendo com a ideia de classe/sala/escola especial para determinado grupo de alunos com deficiência. No entanto, registra-se que essa prática 
ainda não acontece na rede em modo pleno, apenas foi indicada na legislação municipal como diretriz a ser seguida, em função de que essas iniciativas envolvem grupos diferenciados de alunos: alguns em fase inicial de escolarização e outros com muitos anos de institucionalização nos serviços especializados.

No ano de 2013, o CME publicou a Resolução CME no 19 de 2013, que regulamenta a educação especial na perspectiva da escola inclusiva, na Educação Infantil, Ensino Fundamental e modalidade Educação de Jovens e Adultos do município de Cachoeirinha e dá outras providências (CACHOEIRINHA, 2013a). Tal Resolução referenda a intenção do CME de tornar a educação inclusiva uma proposta a ser assumida pela rede pública municipal e Sistema Municipal de Ensino, em seus níveis e modalidades.

No artigo $2^{\circ}$, explicita-se que "a educação especial se realiza em todos os níveis, etapas e modalidades de ensino, tendo o Atendimento Educacional Especializado (AEE) como parte integrante do processo educacional" (CACHOEIRINHA, 2013a). Admite-se, portanto, que a mantenedora assume a responsabilidade do AEE para os alunos que necessitarem, após avaliação do Centro, serem matriculados em classe comum da rede regular do ensino e no AEE, configurando dupla matrícula e sendo registrado no Censo Escolar MEC/INEP. O Centro, logo, configura-se na rede como o responsável pela avaliação diagnóstico-pedagógica do aluno com deficiência, novo na rede, investigando o caso e emitindo parecer técnico-pedagógico, fazendo os encaminhamentos para a escola de destino do aluno.

O Conselho Municipal de Educação de Cachoeirinha acompanhou, no ano de 2011, a desativação da escola especial, orientando quanto ao processo legal de encerramento das atividades da escola e arquivamento de documentação dos alunos matriculados. O município de Cachoeirinha, nesse ano, atendia aproximadamente 300 alunos em SRM, e 86 alunos eram atendidos na escola especial quando foi descredenciada. Desses 86, apenas quinze permaneceram com indicação de matrícula no Centro para o ano seguinte (CACHOEIRINHA, 2011c). Os demais alunos da escola especial, conforme orientação da Secretaria, foram matriculados nas escolas regulares e avaliados quanto à permanência na SRM ou encaminhamento para o Centro. Muitos receberam indicação de matrícula também no Centro, mantendo seu vínculo nesse espaço complementar.

No ano de 2013, foram aprovados pelo CME de Cachoeirinha o Regimento e o Projeto Político-Pedagógico do Centro Municipal de Atendimento Educacional Especializado (CACHOEIRINHA, 2013b, 2013c), elaborado pela equipe e pela comunidade docente que atuam no Centro. Destacam-se alguns pontos significativos para este estudo, no intuito de analisar as linhas orientadoras da constituição da proposta pedagógica do Centro de Atendimento Educacional Especializado.

Primeiramente, com relação ao objetivo geral do Centro, encontra-se no projeto pedagógico:

Promover atendimento pedagógico a crianças, adolescentes e jovens adultos, com deficiência e/ou transtorno global de desenvolvimento, associados ou não à deficiência mental. Prioriza-se o atendimento educacional especializado individualizado, ou por grupos de trabalho, através de laboratórios, de acordo com as necessidades, peculiaridades e características dos educandos (CACHOEIRINHA, 2013c, p.2). 
No que se refere às finalidades do Centro, o projeto pedagógico define:

[....] viabilizar suporte técnico-pedagógico ao processo de inclusão escolar; desenvolver açôes que respeitem e valorizem a singularidade de cada sujeito na aprendizagem escolar no âmbito da educação inclusiva; promover espaços de aprendizagem que oportunizem a adaptação social e bem-estar dos educandos, oportunizar espaços que favoreçam o estímulo e o respeito às diferenças; viabilizar através de parcerias o apoio familiar (CACHOEIRINHA, 2013b, p.2).

Sobre o que diz respeito ao alunado, define-se no Regimento do Centro que o mesmo atende "alunos com diferentes patologias, síndromes, transtorno global do desenvolvimento associados ou não à deficiência mental". Esta identificação mostra-se diferente daquela predominante na história da escola especial, pois ao longo de seus 34 anos de existência teve como orientação o atendimento a alunos com deficiência mental. Essa mudança que aconteceu no ano de 2005, quando se realizou o desligamento de 25 alunos em função da faixa etária, oportunizou que alunos com outras tipologias fossem inseridos na escola especial, especialmente aqueles com transtornos globais do desenvolvimento, alterando o perfil do alunado atendido neste espaço. Podemos supor que essa ampliaçáo do grupo de alunos esteja vinculada à existência de demanda e ao debate político posterior aos anos de 2005 a 2007, com a nova definição de sujeitos público alvo da educação especial.

O documento do projeto pedagógico, nos princípios e fins, retoma a tipologia do alunado ao indicar a idade de quatro anos como inicial para atendimentos no Centro para alunos com "deficiência visual, auditiva, surdocegueira, física, intelectual e múltipla, transtorno global do desenvolvimento, altas habilidades/superdotação," matriculados na rede pública municipal de ensino, preferencialmente até os 21 anos de idade (CACHOEIRINHA, 2013c).

No que se refere à modalidade pedagógica ofertada no Centro

[...] a instituiçẫo está organizada na modalidade de laboratórios, nos quais os educandos poderão ser atendidos individualmente, em pequenos grupos ou em grupos de até oito educandos, observadas as peculiaridades de cada aluno e a suportabilidade de permanecer em espaços de atendimento" (CACHOERINHA, 2013c, p.4).

Os laboratórios atendem os alunos no turno inverso ao da escola e são assim definidos: Corpo e Linguagem, Vivências e Cultura, Arte e Expressão, Informática, Letramento e Saber, Laboratório de Desenvolvimento, Educação Terapêutica (Espaço Terapêutico e Atendimento Terapêutico).

Em relação à reconfiguração da educação especial observada na rede municipal de Cachoeirinha, destacam-se alguns pontos como elementos constitutivos desse processo. O AEE passa a ser complementar ou suplementar e perde, efetivamente, o caráter substitutivo ao se configurar como ofertado nas SRM e no Centro para alunos com deficiência matriculados na rede regular de ensino. A dupla matrícula, utilizada como referência legal para o convencimento da comunidade, por meio do diálogo, manifesta-se como eixo importante no entendimento dessa nova configuração. Da mesma forma, muda o perfil do alunado do Centro e a construção da proposta pedagógica voltada para os alunos com deficiência atendidos nesta modalidade evidencia a necessidade de investir em formação continuada para os profissionais da rede que atuam na educação especial. Observam-se inúmeros pontos de tensão e perspectivas de novas 
possibilidades com a constituição do Centro, a complexidade se manifesta nos desafios e no processo que envolve inúmeros atores e se (re)configura na prática, a partir da ressignificação do já existente e da configuração do novo.

\section{Conclusốes}

No início desse artigo indicamos como objetivo central a busca de compreender o processo de reconfiguração das proposições que vinculam a educação especial e a educação regular dos alunos com deficiência, com atenção especial dirigida à reconfiguraçáo dos espaços de atendimento escolar. Além disso, apresentamos as seguintes questões: como avançar em relação ao que se estabeleceu a partir da Política Nacional de Educação Especial (BRASIL, 2008a), que define que os alunos com deficiência devem ser incluídos na rede regular de ensino? Como tornar a educação especial complementar ou suplementar e não mais substitutiva? Que caminhos, que transição seria possível com base nesta premissa?

Ao analisarmos a trajetória específica de uma rede de ensino, observa-se, no que diz respeito à sintonia com as políticas, que há diferentes movimentos que mostram as possíveis relaçóes entre os diferentes planos da gestão pública. Na prática local, configuram-se ênfases a alguns aspectos referentes a pontos considerados significativos para a rede municipal de ensino em questão, como a matrícula dos alunos com deficiência na rede regular. $\mathrm{O}$ contexto legal nacional foi evocado para dar suporte à argumentação com as famílias dos alunos da escola especial e com os professores e demais profissionais, com o objetivo de justificar o encerramento das atividades da escola especial e a criação do centro de atendimento. A mudança de rumo na configuração da educação especial acontece a partir do momento em que se decide pela dupla matrícula, na escola regular e no AEE, nas SRM ou no Centro, tornando o atendimento especializado complementar ou suplementar ao ensino regular e não mais substitutivo.

A pesquisa mostrou ainda que, em sintonia com o processo decisório recente de fortalecimento da oferta de serviços públicos aos alunos com deficiência, existe um processo histórico que faz da educação especial parte da gestão municipal da educação. De fato, o município de Cachoeirinha assume, desde a década de 1970, mesmo que com reduzido número na oferta, o atendimento aos alunos com deficiência na rede pública de ensino. Na década de 2000, o município aderiu ao Programa de Implantação de Salas de Recursos Multifuncionais (BRASIL, 2007), do MEC, e passou a designar espaço físico e a indicar professores especializados para atuarem nesses locais, nas escolas regulares. Paralelamente, a rede manteve a escola especial, diferenciando os encaminhamentos e atendimentos com base nas características individuais do aluno com deficiência.

As mudanças recentes na configuração dos serviços estão vinculadas à constituição de um Fórum de Discussão no município para tratar do Atendimento Educacional Especializado. A decisão dos gestores, com apoio desse fórum, referendou um momento de reestruturação da educação especial na rede, com a transformação da escola especial em centro de atendimento.

Entendemos que esta seja uma possibilidade futura para a reconfiguração do AEE na rede municipal, uma vez que a aprendizagem dos alunos com deficiência deveria ter como espaço privilegiado as classes comuns na rede regular de ensino. $\mathrm{O}$ fato de se ofertar no contraturno o AEE nas SRM e no Centro se constitui como uma base de apoio e não deve indicar que a 
aprendizagem dos alunos com deficiência estaria condicionada a ocorrer prioritariamente nesses espaços. Essa compreensão limitadora é um risco contínuo que, de certa forma, é frequente em função da existência de recursos e estratégias supostamente adequadas às necessidades de ensino para esses alunos.

Restam questôes que mereceriam novas buscas de esclarecimento e que não puderam ser respondidas em função da tipologia de pesquisa empreendida. Como são significados os diferentes espaços de oferta do atendimento educacional especializado? O que justificaria o encaminhamento do aluno com deficiência para o Centro ou para as salas de recursos? Como a instituição de uma política insere novas diretrizes e, contemporaneamente, se alimenta do conhecimento existente no tecido social de referência?

A abordagem do ciclo de políticas permitiu perceber o quanto as disputas internas por concepçóes e por propostas pedagógicas foram pautadas pelo discurso alinhado com a Política Nacional de Educação Especial na perspectiva da Educação Inclusiva (BRASIL, 2008a), mas reinterpretado no contexto local. Essa sintonia mostra-se nas diretrizes, nas definiçôes de sujeitos e na elaboração dos dispositivos normativos locais analisados ao longo do texto. Considera-se, portanto, um processo de reorganização que permitiu aos diferentes atores lidarem com as decisôes tomadas em diversas instâncias da gestão local, assumindo posiçôes e manifestando-se no que diz respeito à forma como compreendem os movimentos que se traduzem em efeitos como a criação do centro de atendimento e a completa redefinição das atividades da escola especial.

Nesse sentido, considerando as dimensóes do território brasileiro, a pluralidade de nossas experiências e a necessária articulação entre os entes federados na instituição de políticas sociais, acredita-se que a realização de estudos desta natureza, analisando as singularidades de processo decisório, possa contribuir para subsidiar a formulação de políticas públicas, bem como contribuir para a qualificação de propostas de intervenção que favoreçam a inclusão escolar.

\section{REFERÊNCIAS}

BALL, S. Entrevista com Stephen Ball: um diálogo sobre justiça social, pesquisa e política educacional. Educação e Sociedade. Campinas, v.30, n.106, p.303-318, 2009. Entrevista concedida a Jéferson Mainardes e Maria Inês Marcondes.

BALL, S. Sociologia das políticas educacionais e pesquisas crítico-social: uma revisão pessoal das políticas educacionais e da pesquisa política educacional. Currículo sem Fronteiras, v.6, n.2, p.10-32, 2006.

BALL, S. Education reform: a critical and post-structural approach. Buckinghan: Open University Press, 1994.

BALL, S.; BOWE, R. Subject departments and 'implementation' of National Curriculum policy: an overview of the issues. Journal of Curriculum Studies, v.24, n.2, p.97-115, 1992.

BAPTISTA, C. R. Ação pedagógica e Educação especial: a sala de recursos como prioridade na oferta de serviços especializados. Revista Brasileira de Educação Especial, Marília, v.17, p.59-76, 2011.

BRASIL. Ministério da Educação. INEP. EDUCACENSO 2013. Disponível em: <http://inep.gov.br>. Acesso em: 20 dez. 2013. 
BRASIL. Decreto $n^{\circ} 7.611$, de 17 de novembro de 2011. Dispóe sobre a Educação especial, o Atendimento Educacional especializado e dá outras providências. 2011a. Disponível em: < http://www. planalto.gov.br/ccivil_03/_Ato2011-2014/2011/Decreto/D7611.htm>. Acesso em: 16 nov. 2013.

BRASIL. Ministério da Educação. Política nacional de educaçâo especial na perspectiva da educação inclusiva. Brasília, DF: MEC, 2008a.

BRASIL. Decreto $n^{\circ}$ 6.571, de 17 de setembro de 2008. Dispóe sobre o atendimento educacional especializado, regulamenta o parágrafo único do art. 60 da Lei no 9.394, de 20 de dezembro de 1996, e acrescenta dispositivo ao Decreto no 6.253, de 13 de novembro de 2007. 2008b. Disponível em: <http:// www.planalto.gov.br/ccivil_03/_ato2007-2010/2008/Decreto/D6571.htm>. Acesso em: 16 nov.2013.

BRASIL. Ministério da Educação, Secretaria de Educação Especial. Programa de implantação das salas de recursos multifuncionais. Brasília, DF: Ministério da Educação, 2007.

BRASIL. Conselho Nacional de Educação - Câmara de Educação Básica. Parecer CNE/CEB no 17, de 03 de julho de 2001. Diretrizes Nacionais para a Educação Especial na Educação Básica. 2001a. Diário Oficial [da] República Federativa do Brasil, Brasília, DF, 17 ago. 2001. Seção 1, p.46.

BRASIL. Conselho Nacional de Educação - Câmara de Educação Básica. Resolução CNE/CEB no 2, de 11 de setembro de 2001. Institui Diretrizes Nacionais para Educação Especial na Educação Básica. 2011b. Disponível em: <http://portal.mec.gov.br/cne/arquivos/pdf/CEB0201.pdf>. Acesso em: 16.nov.2013.

BRASIL. Constituição (1988). Constituição da República Federativa do Brasil. Brasília, DF: Senado Federal, 1988.

BRASIL. IBGE. Censo demográfico: infográficos: escolas, docentes e matrículas de Cachoeirinha. Rio Grande do Sul, 2010. Disponível em: <http://cidades.ibge.gov.br/painel/educacao.php?lang=\&codm un $=430310 \&$ search=rio-grande-do-sul|cachoeirinha|infograficos:-escolas-docentes-e-matriculas-pornivel>. Acesso em: 13 ago. 2013.

CACHOEIRINHA. Conselho Municipal de Educação de Cachoerinha (CME). Resolução CME no 19, de 19 de março de 2013. Regulamenta a Educação Especial na perspectiva da Escola Inclusiva, na Educação Infantil, Ensino Fundamental e Modalidade Educação de Jovens e Adultos do Município de Cachoeirinha e dá outras providências. Cachoeirinha: Conselho Municipal de Educação, 2013a.

CACHOEIRINHA. Secretaria Municipal de Educação de Cachoeirinha. Regimento do Centro Municipal de Atendimento Educacional Especializado Lampadinha. Cachoeirinha: Secretaria Municipal de Educação, 2013b.

CACHOEIRINHA. Secretaria Municipal de Educação de Cachoeirinha. Proposta Pedagógica do Centro Municipal de Atendimento Educacional Especializado Lampadinha. Cachoeirinha: Secretaria Municipal de Educação, 2013c.

CACHOEIRINHA. Conselho Municipal de Educação de Cachoerinha (CME). Resolução CME $n^{o} 18$, de 26 de novembro de 2012. Estabelece normas para o credenciamento e Autorizaçáo para funcionamento dos Centros de Atendimento Educacional Especializado e dá outras providências. Cachoeirinha: Conselho Municipal de Educação, 2012.

CACHOEIRINHA. Conselho Municipal de Educação de Cachoeirinha (CME). Informativo no 1 , ano1, Prefeitura Municipal de Educação de Cachoeirinha, 2011 a.

CACHOEIRINHA. Secretaria Municipal de Educação. Educar, a revista da Educação, v.2, n 2, 2011 b. 
CACHOEIRINHA. Conselho Municipal de Educação de Cachoeirinha (CME). Parecer no 23, de 18 de novembro de 2011. Cessação do efeito da credencial de autorização para funcionamento da EMEF, modalidade educação especial, Lampadinha, cancelando o credenciamento para oferta. Cachoeirinha: Conselho Municipal de Educaçáo, 2011c.

CACHOEIRINHA. Secretaria Municipal de Educação (SMEd). Relatório Final Educação Especiall Inclusão. Cachoeirinha: Secretaria Municipal de Educação, 2011d.

CACHOEIRINHA. Secretaria Municipal de Educação (SMEd). Ata no 4 de reunião do grupo de trabalho. Cachoeirinha: Secretaria Municipal de Educação, 2011 e.

CACHOEIRINHA. Secretaria Municipal de Educação (SMEd). II Constituinte Escolar. Cachoeirinha: Secretaria Municipal de Educação, 2010.

CARVALHO, J. M. Cidadania no Brasil: o longo caminho. Rio de Janeiro: Civilização Brasileira, 2003.

FERrEIRA, A. B. H. Novo Dicionário Aurélio de Lingua Portuguesa. Curitiba: Positivo, 2004.

MARQUES, A. Da escola especial ao centro de atendimento especializado: um olhar em movimento. 2012. Monografia (Especialização em Educação Especial e Processos Inclusivos) - Programa de PósGraduação Lato Sensu em Educação, Universidade Federal do Rio Grande do Sul, Porto Alegre, 2012.

MAINARDES, J. A abordagem do ciclo de políticas: uma contribuição par a análise de políticas educacionais. Educação e Sociedade, Campinas, v.27, n. 94, p.47-69, 2006.

MAINARDES, J. Análise de políticas educacionais: breves consideraçôes teórico-metodológicas. Contrapontos, Itajaí, v.9, n.1, p.4-16, 2009.

MAINARDES, J.; FERREIRA, M. S.; TELLO, C. Análise de políticas: fundamentos e principais debates teóricos-metodológicos. In: BALL, S.; MAINARDES, J. (Org.). Políticas educacionais: questóes e dilemas. São Paulo: Cortes, 2011.

VASQUES, C.; MARQUES, A. Da escola especial ao centro de atendimento educacional especializado: olhares em movimento. Poiésis, UNISUL, Tubarão, v.6, n.10, p.411-422, 2012.

Recebido em: 23/03/2016

Reformulado em: 13/07/2016

Aprovado em: 18/07/2016 